\title{
PENERAPAN METODE STRUKTURAL ANALITIK SINTETIK (SAS) DALAM MEMBACA PERMULAAN SISWA KELAS II SDN 004 BATURIJAL HULU
}

\author{
Aida Nursanti \\ Guru SDN 004 Baturijal Hulu, Kecamatan Peranap, \\ Kabupaten Indragiri Hulu, Riau \\ nursantiaida171@gmail.com
}

\begin{abstract}
This research was motivated by the low ability of students to read at the beginning, so the researchers applied the SAS method in order to help students who still had difficulty reading. This study aims to determine the difference between the pretest and posttest by applying the synthetic analytical structural method (SAS) in reading the beginning of grade II elementary school students and to determine the increase in the pretest and posttest in reading the beginning of students. This type of research is a type of pretest-posttest one group preexperimental design, which is an experiment that is only carried out in one group, without comparison. This research was carried out in class II SDN 004 Baturijal Hulu, Peranap sub-district with a total of 29 students. Based on the research results, it was found that the average value of reading ability before being treated (pretest) was 51.68 while the average value of reading ability after treatment (posttest) was 88.65 and the average value of normality gain was 0.76 which including the high category and the results of hypothesis testing using t-test with $t$ $=47.191$ and $t$ table $=2.045$, it is concluded that $t$ count $>t$ table, then reject $H O$ means significant. This means that there is a significant increase in pre-test reading in grade II students between before (pretest) and after (posttest) applying the Synthetic Structural Analytical (SAS) method.
\end{abstract}

Keywords: SAS method, read beginning, elementary school

\begin{abstract}
Abstrak: Penelitian ini dilatar belakangi karena rendahnya kemampuan membaca permulaan siswa, sehingga peneliti menerapkan metode SAS agar dapat membantu siswa yang masih sulit membaca. Penelitian ini bertujuan untuk mengetahui perbedaan pretest dan posttest dengan menerapkan metode struktural analitik sintetik (SAS) dalam membaca permulaan siswa kelas II SD dan untuk mengetahui peningkatan pretest dan posttest dalam membaca permulaan siswa. Jenis penelitian ini adalah jenis pretest-posttest one group design pra eksperimen, merupakan eksperimen yang hanya dilakukan hanya pada satu kelompok, tanpa perbandingan. Penelitian ini dilaksanakan di kelas II SDN 004 Baturijal Hulu kecamatan peranap dengan jumlah 29 siswa. Berdasarkan hasil penelitian ditemukan bahwa nilai rata-rata kemampuan membaca sebelum di beri
\end{abstract}


perlakuan (pretest) adalah 51,68 sementara nilai rata-rata kemampuan membaca sesudah perlakuan (posttest) adalah 88,65 dan nilai rata-rata normalitas gain adalah 0,76 yang termasuk kategori tinggi dan hasil pengujian hipotesis menggunakan uji-t dengan $t_{\text {hitung }}=47,191$ dan $t_{\text {tabel }}=2,045$ maka disimpulkan $t_{\text {hitung }}>t_{\text {tabel, }}$ maka tolak $H_{0}$ berarti signifikan. Ini berarti terdapat peningkatan membaca permulaan pada siswa kelas II yang signifikan antara sebelum (pretest) dan sesudah (posttest) menerapkan metode Struktural Analitik Sintetik (SAS).

Kata Kunci: metode sas, membaca permulaan, sekolah dasar

\section{PENDAHULUAN}

Pembelajaran Bahasa Indonesia sangat berperan dalam proses pendidikan dan juga perkembangan berbahasa. Bahasa sangat penting dan mempunyai hubungan yang luas dan terkait dengan kehidupan manusia dan pemamfaatannya dalam berkomunikasi, untuk itu mata pelajaran Bahasa Indonesia merupakan mata pelajaran yang wajib diajarkan di Sekolah Dasar (SD).

Kemampuan membaca dan menulis di tingkat sekolah dasar adalah bagian dari kemampuan berbahasa. Bahasa adalah sarana untuk memperoleh ilmu dan sekaligus bagian dari budaya, serta sarana berkomunikasi. Kemampuan membaca menjadi dasar yang utama tidak saja bagi pengajaran bahasa Indonesia sendiri, akan tetapi juga bagi pengajaran mata pelajaran lain, oleh karena itu, membaca harus diupayakan semaksimal mungkin agar kelak anak tidak mengalami kesulitan dalam membaca.

Pada dasarnya siswa di kelas II sekolah dasar sudah mampu menulis, tetapi dalam hal membaca banyak siswa yang ternyata belum mampu. Kondisi yang terjadi di kelas II SDN 004 Baturijal Hulu yaitu masih banyak siswa yang belum mampu membaca permulaan, hal ini tentu akan berpengaruh pada hasil belajar siswa yang lainnya. Kemampuan membaca sangat penting, sebab dengan membaca maka pintu-pintu pemahaman akan terbuka bagi siswa.

Kemampuan membaca yang diperoleh pada membaca permulaan akan sangat berpengaruh terhadap kemampuan membaca lanjut, sebagai kemampuan yang mendasari kemampuan berikutnya, kemampuan membaca permulaan benar-benar memerlukan perhatian guru, sebab jika dasar itu tidak kuat, pada tahap membaca lanjut siswa akan mengalami kesulitan untuk dapat memiliki kemampuan membaca yang memadai. Oleh karena itu, guru kelas II haruslah sungguh-sungguh agar ia dapat 
memberikan dasar kemampuan membaca yang memadai kepada anak didik. Dalam pelaksanaan penelitian tindakan kelas ini, peneliti mengambil solusi pemecahan masalah dalam mengatasi rendahnya kemampuan siswa kelas II membaca, peneliti memilih menggunakan metode struktural analitik sintetik (SAS). Dipilihnya metode tersebut karena dalam membaca permulaan bagi siswa kelas II SD masih dalam kategori kelas rendah sehingga diperlukan metode yang tepat yang sesuai dengan teori dalam membaca permulaan diantaranya menggunakan metode di atas.

Berdasarkan latar belakang masalah yang telah diuraikan diatas, maka dirumuskan permasalahan sebagai berikut: (1) Apakah ada perbedaan pretest dan posttest dengan menerapkan metode struktural analitik sintetik (SAS) dalam membaca permulaan siswa kelas II SD?; (2) Apakah ada peningkatan pretest dan posttest dalam membaca permulaan siswa kelas II SD?

Tujuan penelitian ini adalah: (1) Untuk mengetahui perbedaan pretest dan posttest dengan menerapkan metode struktural analitik sintetik (SAS) dalam membaca permulaan siswa kelas II SD; (2) Untuk mengetahui peningkatan pretest dan posttest dalam membaca permulaan siswa kelas II.

Berdasarkan pemasalahan di atas penulis mencoba untuk melakukan penelitian dengan judul "Penerapan Metode Struktural Analitik Sintetik (SAS) dalam Membaca Permulaan Siswa Kelas II SDN 004 Baturijal Hulu Kecamatan Peranap".

Menurut Pratiwi, dkk (2007) bahwa membaca adalah kegiatan berbahasa yang secara aktif menyerap atau informasi atau pesan yang disampaikan melalui media tulis, seperti buku, artikel, modul, surat kabar, atau media tulis lainnya. Disebut aktif karena membaca bukan hanya sekedar memahami lambang tulis, tetapi juga membangun makna, memahami, menerima, menolak, membandingkan, dan meyakini isi tulisan.

Membaca permulaan merupakan tahapan proses belajar membaca bagi siswa sekolah dasar kelas awal. Siswa belajar untuk memperoleh kemampuan dan menguasai teknik-teknik membaca dan menangkap isi bacaan dengan baik. Oleh karena itu, guru perlu merancang pembelajaran membaca dengan baik sehingga mampu menumbuhkan kebiasan membaca sebagai suatu yang menyenangkan. Ada empat langkah dalam mengajar membaca permulaan yaitu: 1). Mengidentifkasi keseluruhan kata, huruf dan bunyi kelompok-kelompok huruf, 2). Mengucapkan bunyi- 
bunyi kelompok huruf dan huruf, 3). Menyajikan kepada anak huruf atau kelompok huruf dan meminta untuk mengucapkannya, 4). Guru mengambil beberapa huruf pada susunan kata tertulis dan anak diminta mengucapkan kelompok huruf yang masih tersusun (Glass dalam Mulyono, 1999).

Membaca permulaan sebagai proses penerjemahan simbol bunyi menjadi bunyi yang bermakna. Dalam membaca permulaan diperlukan proses pengenalan huruf, suku kata, tanda baca, kata, dan kalimat. Ketepatan artikulasi dan Intonasi juga dikembangkan pada tahap membaca permulaan ini (Depdiknas, 2007).

Menurut Solchan (2009), metode Struktural Analitik Sintetik merupakan metode yang mengawali pembelajarannya dengan menampilkan dan memperkenalkan sebuah kalimat utuh. Kalimat utuh yang dijadikan tonggak dasar diuraikan ke dalam satuansatuan bahasa yang lebih kecil yang disebut kata. Proses analisis atau penguraian ini terus berlanjut hingga sampai pada wujud satuan bahasa terkecil yang tidak bisa diuraikan lagi, yakni huruf-huruf. Dipilihnya metode SAS karena siswa mulai melafalkan huruf, suku kata, kata, dan kalimat sederhana dengan menggunakan vokal, lafal dan intonasi yang tepat (Mulyati, 2009).

Menurut Akhadiyah, dkk (1991) langkah-langkah metode Struktural Analitik Sintetik (SAS) ini dilaksanakan dalam dua periode sebagai berikut: a. Periode membaca permulaan tanpa buku, antara lain: (1) merekam bahasa anak; (2) bercerita dengan gambar; (3) membaca gambar; (4) membaca gambar dengan kartu kalimat; (5) proses struktural (s); (6) proses analitik (a); (7) proses sintentik (s) dan b. periode membaca dengan buku

Menurut Hairuddin, dkk (2007) menjelaskan bahwa proses penguraian atau penganalisisan pembelajaran membaca permulaan dengan menggunakan Struktural Analitik Sintetik (SAS), meliputi: a) Kalimat menjadi kata-kata; b.) Kata menjadi sukusuku kata, dan; c) Suku kata menjadi huruf-huruf. Selanjutnya dari huruf, suku kata dan kalimat.

Kelebihan metode SAS menurut Kurniasih dan Sani (2016) yaitu: (1) Metode ini dapat sebagai landasan berfikir analisis; (2) Dengan langkah-langkah yang diatur sedemikian rupa membuat anak mudah mengikuti prosedur dan akan dapat cepat membaca pada kesempatan berikutnya; (3) Berdasarkan landasan linguistik metode ini 
akan menolong anak dalam menguasai bacaan dengan lancar. Metode yang dijelaskan diatas bukanlah metode yang terbaik sebab "tidak ada metode terbaik dan juga tidak ada metode terburuk". Setiap metode memiliki kelebihan dan kekurangan. Metode yang terbaik adalah metode yang cocok dengan peakaiannya, maksudnya yang sesuai dengan karakteristik dan kebutuhan siswa (Kurniaman, O 2016).

\section{METODE PENELITIAN}

Penelitian ini dilaksanakan di kelas II SDN 004 Baturijal Hulu, Kecamatan Peranap, Kabupaten Indragiri Hulu pada semester II tahun pelajaran 2019/2020. Subjek penelitian ini berjumlah 29 orang yang terdiri dari 16 siswa laki-laki dan 13 siswa perempuan. Subjek penelitian di dalam desain ini merupakan sampel yang menurut Donald Ary disebut sebagai "non independent sample" (Arikunto, 2000).

Dilaksanakan penelitian ini pada kelas II karena didasarkan pada pertimbangan antara lain: 1) masih banyak ditemukan siswa yang mengalami kesulitan dalam membaca permulaan; 2) di sekolah ini belum pernah dilakukan penelitian yang menggunakan metode SAS dalam pembelajaran membaca permulaan.

Jenis penelitian ini adalah penelitian kuantitatif dengan metode eksperimen dengan menggunakan desain penelitian one group pretest-posttest design yakni membandingkan nilai pretest dengan nilai posttest di dalam satu kelas. Pada desain ini, sebelum perlakuan yang sebelum perlakuan diberikan terlebih dahulu tes awal (pretest), kemudian diberi perlakuan (treatment) dan selanjutnya diakhir pembelajaran diberi tes akhir (posttest) untuk lebih akurat membandingkan antara keadaan sebelum diberi perlakuan dengan sesudah (Sugiyono, 2016).

Tabel 1. Desain Penelitian

\begin{tabular}{ccc}
\hline $\begin{array}{c}\text { Tes awal } \\
\text { (Pretest) }\end{array}$ & Perlakuan & $\begin{array}{c}\text { Tes Akhir } \\
\text { (Posttest) }\end{array}$ \\
\hline $\mathrm{O}_{1}$ & $\mathrm{X}$ & $\mathrm{O}_{2}$ \\
\hline
\end{tabular}

(Sumber: Sugiyono, 2016)

Teknik pengumpulan data merupakan cara megumpulkan data yang dibutuhkan untuk menjawab rumusan masalah penelitian (Noor, J 2011). Teknik pengumpulan data dalam penelitian ini menggunakan teknik tes, dengan data yang dikumpulkan 
dalam penelitian ini diambil dari hasil pretest dan postest siswa, perbedaan skor pretest dan posttest siswa terhadap metode SAS dan peningkatan skor pretest dan posttest membaca permulaan siswa.

Untuk mengumpulkan data dalam penelitian ini, maka digunakan instrumen soal tes awal dan soal tes akhir yang terdiri dari lima kalimat sederhana yang disertai gambar, dimana soal pretest dan postest tersebut telah di uji validitasnya oleh ahli (expert judgment). Soal pretest dan posttest yang digunakan dalam penelitian ini adalah soal yang sama.

Teknik analisis data digunakan untuk menguji keberhasilan penelitian. Teknik analisis data yang digunakan dalam penilitian ini menggunakan rumus statistik sebagai berikut:

1. Skor hasil tes tiap siswa

Skor yang diperoleh siswa dari tes di konversikan dalam bentuk nilai dengan rentang 0-100 dengan menggunakan rumus:

Nilai Akhir $=\frac{\text { jwmilah skor yang di peroleh siswa }}{\text { shor maksimun }} \times 100$, (Sudjana, 2005)

2. Menghitung rata-rata $(\overline{\mathrm{x}})$ skor hasil pretest dan posttest dengan rumus:

$\overline{\mathrm{x}}=\frac{\sum x i}{\mathrm{n}},($ Supardi, 2013)

3. Menghitung standar devisiasi (s) dengan rumus:

$S=\sqrt{\frac{\sum x i^{2}-\frac{\left(\sum x i\right) x}{n}}{n-1}},($ Supardi, 2013)

4. Menghitung varians $\left(s^{2}\right)$ dengan rumus:

$s^{2}=\frac{\sum x i^{2}-\frac{(2 x i) x}{n}}{n-1}$, (Supardi, 2013)

5. Uji normalitas dengan menggunakan (kolmogorov smirnov)

6. Uji Homogenitas dengan rumus:

$F_{\text {hitung }}=\frac{\text { Varian Besay }}{\text { Variankeril }},($ Sundayana, 2014)

7. Uji perbandingan (uji t) dengan rumus:

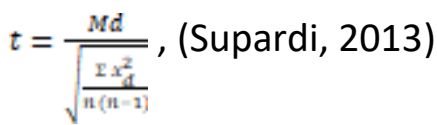

8. Peningkatan kompetensi yang terjadi sebelum dan setelah pembelajaran dihitung dengan rumus gain ternormalisasi (normalized gain), yaitu: 
$\mathrm{g}=\frac{\text { skor posttest-skor pretest }}{\text { skor ideal-skor pretest }}, \quad$ (Sundayana, 2014)

Kategori gain ternormalisasi (g) berpedoman pada standar dari Hake dalam Sundayana (2014) dapat dilihat pada tabel 2 dibawah ini:

Tabel 2. Kategori Gain Ternormalisasi

\begin{tabular}{cc}
\hline Nilai Gain Ternormalisasi & Interpretasi \\
\hline$-1,00 \leq \mathrm{g}<0,00$ & Terjadi penurunan \\
\hline $\mathrm{g}=0,00$ & Tidak terjadi penurunan \\
\hline $0,00<\mathrm{g}<0,30$ & Rendah \\
\hline $0,30 \leq \mathrm{g}<0,70$ & Sedang \\
\hline $0,70 \leq \mathrm{g} \leq 1,00$ & Tinggi \\
\hline
\end{tabular}

(Sumber: Sundayana, R 2014)

\section{HASIL DAN PEMBAHASAN}

\section{Data Pretest dan Posttest}

Hasil tes awal (pretest) adalah kemampuan membaca siswa SD, dimana siswa belum diberikan perlakuan dengan metode struktural analitik sintetik (SAS). Hasil test awal (pretest) dapat dilihat pada tabel 3 berikut:

Tabel 3. Data Hasil Kemampuan Membaca pada Tes Awal (Pretest)

\begin{tabular}{|c|c|c|c|c|c|c|}
\hline Data & $\begin{array}{c}\text { Jumlah } \\
\text { Siswa } \\
\text { (n) }\end{array}$ & $\begin{array}{l}\text { Rata-rata } \\
\qquad(\bar{x})\end{array}$ & $\begin{array}{c}\text { Standar } \\
\text { Deviasi (s) }\end{array}$ & Varians $\left(s^{2}\right)$ & $\begin{array}{l}\text { Nilai } \\
\text { Min }\end{array}$ & $\begin{array}{l}\text { Nilai } \\
\text { Max }\end{array}$ \\
\hline Pretest & 29 & 51,68 & 2,6558 & 7,0534 & 46,78 & 55,97 \\
\hline
\end{tabular}

(Sumber: Olahan data)

Berdasarkan tabel 3 dapat diketahui bahwa rata-rata siswa sebelum tindakan adalah 51,68. Nilai maksimal adalah 55,97 dan nilai minimal adalah 46,78 , serta Standar Deviasi 2,6558, Varians 7,0534. Sedangkan untuk data posttest dapat dilihat pada tabel 4 dibawah ini: 
Tabel 4. Data Hasil Kemampuan Membaca pada Tes Akhir (Posttest)

\begin{tabular}{ccccccc}
\hline \multirow{2}{*}{ Data } & $\begin{array}{c}\text { Jumlah Siswa } \\
\text { (n) }\end{array}$ & $\begin{array}{c}\text { Rata-rata } \\
(\mathbf{x})\end{array}$ & $\begin{array}{c}\text { Standar } \\
\text { Deviasi }(\mathbf{s})\end{array}$ & $\begin{array}{c}\text { Varians } \\
\left(\mathbf{s}^{2}\right)\end{array}$ & $\begin{array}{c}\text { Nilai } \\
\text { Min }\end{array}$ & $\begin{array}{c}\text { Nilai } \\
\text { Max }\end{array}$ \\
\hline Posttest & 29 & 88,65 & 2,3390 & 5,4790 & 83,75 & 92,65 \\
\hline
\end{tabular}

(Sumber: Olahan data)

Berdasarkan tabel 4 dapat diketahui bahwa rata-rata siswa setelah diberi perlakuan adalah 88,65. Nilai maksimal adalah 92,65 dan nilai minimal adalah adalah 83,75 , standar deviasi 2,3390 serta varians 5,4790.

\section{Uji Normalitas Skor Pretest dan Posstest}

Uji normalitas data ini dilakukan dengan menggunakan Kolmogorov-Smirnov. Uji normalitas digunakan untuk mengetahui normalitas data skor tes awal dan data skor akhir dengan perumusan hipotesis sebagai berikut :

$$
\begin{array}{ll}
\mathrm{H}_{0} & \text { : data berdistribusi normal } \\
\mathrm{H}_{1} & \text { : data tidak berdistribusi normal }
\end{array}
$$

dengan kriteria pengujian :

Tolak $\mathrm{H}_{0} \mathrm{jika} \mathrm{a}_{\max }>\mathrm{D}_{\text {tabel }}$ dan

Terima $\mathrm{H}_{0} \mathrm{j}_{\mathrm{i}} k \mathrm{a} \mathrm{a}_{\max } \leq \mathrm{D}_{\text {tabel }}$

Pengujian hipotesis menggunakan taraf signifikan $\alpha=0,05$ dan $D_{\text {tabel }}=0,2332$ (dilihat pada tabel D untuk uji Kolmogorov-Smirnov sampel tunggal) dengan kriteria jika $\mathrm{a}_{\max } \leq \mathrm{D}_{\text {tabel }}$ maka $\mathrm{H}_{0}$ diterima dan disimpulkan bahwa data berdistribusi normal.

Adapun hasil perhitungan uji normalitas terhadap tes awal (pretest) dan tes akhir (posttest) dapat dilihat pada tabel 5 berikut:

Tabel 5. Hasil Uji Normalitas Pretest dan Posttest Kemampuan Membaca

\begin{tabular}{ccccc}
\hline \multirow{2}{*}{ Tes } & \multicolumn{3}{c}{ Normalitas } & \multirow{2}{*}{ Keputusan } \\
\cline { 2 - 4 } & $\mathbf{N}$ & $\mathbf{a}_{\text {maks }}$ & $\mathbf{D}_{\text {tabel }}$ & \\
\hline Awal (pretest) & 29 & 0,1247 & 0,2525 & Normal \\
Akhir (posttest) & 29 & 0,0644 & 0,2525 & Normal \\
\hline
\end{tabular}

(Sumber: Olahan data) 
Berdasarkan tabel 5 dapat diketahui bahwa skor awal (pretest) yaitu $\mathrm{a}_{\text {maks }}=$ 0,1247 dan $\mathrm{D}_{\text {tabel }}=0,2525$ maka $\mathrm{a}_{\text {maks }}<\mathrm{D}_{\text {tabel }}$ sehingga berdistribusi normal. Skor tes akhir (posttest) yaitu $\mathrm{a}_{\text {maks }}=0,0644$ dan $\mathrm{D}_{\text {tabel }}=0,2525$ maka $\mathrm{a}_{\text {maks }}<\mathrm{D}_{\text {tabel }}$ sehingga berdistribusi normal. Adapun Gain kemampuan membaca berjumlah 22,14 dengan rata-rata Gain sebesar 0,76. Gain kemampuan membaca siswa kelas II SD yang diperoleh sebesar 0,76 termasuk pada kategori tinggi.

\section{Uji Homogenitas Data}

Berdasarkan uji normalitas, diketahui tes awal, tes akhir, dan N-Gain berdistribusi normal, maka selanjutnya dapat dilakukan uji homogenitas. Pengujian homogenitas data ini dilakukan dengan teknik uji F (Fisher) dengan cara membandingkan varians data terbesar dan terkecil.

Perumusan hipotesis pengujian homogenitas sebagai berikut :

$$
\begin{aligned}
& H_{0} \text { : Kedua varians homogen }\left(v_{1}=v_{2}\right) \\
& H_{a} \text { : Kedua varians tidak homogen }\left(v_{1} \neq v_{2}\right)
\end{aligned}
$$

Dengan taraf signifikan $\alpha=0,20 \quad F_{\text {hitung }}=0,776$ dan $F_{\text {tabel }}=1,7878$ maka $F_{\text {hitung }}<F_{\text {tabel }}$ sehingga $\mathrm{H}_{\mathrm{o}}$ diterima berarti varians kedua data homogen. Dengan kriteria sebagai berikut:

Jika $F_{\text {hitung }}<F_{\text {tabel }}$, maka Ho diterima berarti varians homogen.

Jika $F_{\text {hitung }}>F_{\text {tabel }}$, maka Ho ditolak berarti varians tidak homogen.

Tabel 6. Hasil Uji Homogenitas Kemampuan Membaca

\begin{tabular}{ccccc}
\hline \multirow{2}{*}{ Data } & \multicolumn{3}{c}{ Homogenitas } & \multirow{2}{*}{ Keputusan } \\
\cline { 2 - 3 } & Varians & $\boldsymbol{F}_{\text {hitung }}$ & $\boldsymbol{F}_{\text {tabel }}$ & \\
\hline Pretest & 7,0534 & 0,776 & 1,7878 & Homogen \\
\cline { 1 - 2 } & 5,4709 & & & Homogen \\
\hline
\end{tabular}

(Sumber: Olahan data)

Berdasarkan tabel 6 dapat diketahui bahwa setelah setelah dilakukan uji homogenitas pada nilai tes awal dan tes akhir didapatkan $F_{\text {hitung }}<F_{\text {tabel }}$ atau 0,776< 1,7878. Hal ini berarti varians bersifat homogen atau dapat dilanjutkan dengan uji t. 


\section{Uji t Pretest dan Posttest}

Berdasarkan uji normalitas terhadap nilai awal (pretest) dan nilai tes akhir (posttest) diperoleh bahwa kemampuan membaca siswa berdistribusi normal. Selanjutnya dilakukan uji t untuk mengetahui ada atau tidaknya perbedaan signifikan antara nilai rata-rata awal (pretest) dan nilai rata-rata akhir (posttest). Untuk menganalisis perbedaan antara nilai pretest dan posttest kemampuan membaca siswa menggunakan pretest dan posttest one group design, maka dilakukan pengujian hipotesis komparasi dengan uji-t sebagai berikut :

$$
t=\frac{M d}{\sqrt{\frac{\sum x_{\mathbb{d}}^{n}}{n(n-1)}}}, \text { (Supardi, 2013) }
$$

dengan hipotesis sebagai berikut:

Tolak $\mathrm{H}_{0}$ jika $\mathrm{t}_{\text {hitung }}>\mathrm{t}_{\text {tabel }}$ dan

Terima $\mathrm{H}_{0}$ jika $\mathrm{t}_{\text {hitung }}<\mathrm{t}_{\text {tabel }}$

Tabel 7. Uji t Skor Pretest Dan Posttest

\begin{tabular}{ccccccc}
\hline $\mathbf{N}$ & $\mathbf{M d}$ & $\mathbf{\Sigma x d}^{\mathbf{2}}$ & $\mathbf{t}_{\text {tabel }}$ & $\mathbf{t}_{\text {hitung }}$ & Hipotesis & Kesimpulan \\
\hline 29 & 36,97 & 498,47 & 2,045 & 47,191 & Tolak $\mathrm{H}_{\mathrm{o}}$ & Signifikan \\
\hline
\end{tabular}

(Sumber: Olahan data)

Berdasarkan tabel 7 dapat dilihat bahwa $t_{\text {hitung }}=47,191$ dan $t_{\text {tabel }}=2,045$ kemudian $t_{\text {hitung }}$ dibandingkan dengan $t_{\text {tabel }}$ dapat disimpulkan $t_{\text {hitung }}>t_{\text {tabel, }}$ yang berarti tolak $H_{0}$ artinya signifikan.

\section{N-Gain}

Besarnya peningkatan membaca siswa sebelum dan setelah pembelajaran dihitung dengan rumus gain ternormalisasi (normalized gain). N-Gain bertujuan untuk mengetahui peningkatan kemampuan membaca sebelum dan sesudah perlakuan diberikan yaitu dengan penerapan metode struktural analitik sintetik (SAS). Adapun NGain kemampuan membaca berjumlah 22,14 dengan rata-rata N-Gain sebesar 0,76. Gain kemampuan membaca siswa kelas II SD yang diperoleh sebesar 0,76 termasuk pada kategori tinggi. 


\section{Pembahasan}

Penelitian ini merupakan penelitian eksperimen dengan design One Group PretestPosttest Design, yaitu model penelitian ini memberikan perlakuan pada satu kelompok saja tanpa kelompok pembanding. Di dalam desain ini, pengukuran dilakukan sebanyak 2 kali yaitu sebelum eksperimen (pretest) dan sesudah eksperimen (posttest). Pada saat tes awal siswa membaca menggunakan media kartu kalimat metode SAS tetapi belum diberikan perlakuan, sedangkan pada tes akhir siswa membaca menggunakan media kartu kalimat metode SAS. Penelitian ini bertujuan untuk mengetahui perbedaan pretest dan posttest dengan menerapkan metode struktural analitik sintetik (SAS) dalam membaca permulaan siswa kelas II sekolah dasar dan untuk mengetahui peningkatan pretest dan posttest dalam membaca permulaan siswa.

Pada penelitian ini yang menjadi subjek peneltian adalah kelas II pada SDN 004 Baturijal Hulu yang berjumlah 29 orang, Pembelajaran dilaksanakan 6 kali pertemuan. Pertemuan pertama melaksanakan tes awal (Pretest), Pertemuan kedua sampai kelima menyampaikan materi pembelajaran. Setelah mengalami proses pembelajaran sebanyak empat kali pertemuan dengan metode SAS selanjutnya siswa diberikan tes akhir (Posttest). Pemberian posttest bertujuan untuk mengetahui perbedaan kemampuan siswa dengan menerapkan metode struktural analitik sintetik (SAS) dan peningkatan membaca siswa sebelum dan setelah diberikan perlakuan.

Berdasarkan hasil skor pretest dan posttest memiliki peningkatan rata-rata dari 51,68 dengan standar deviasi 2,6558 menjadi 88,65 dengan standar deviasi 2,3390. Berdasarkan perbedaan rata-rata antara pretest dan posttest tersebut dapat dilihat bahwa terdapat perbedaan kemampuan membaca siswa setelah menerapkan metode SAS. Perbedaan ini didasarkan pada hasil uji $t$, diperoleh $t$ hitung yang memenuhi kriteria yaitu $t_{\text {hitung }}>t_{\text {tabel }}$ atau 47,191 $>2,045$. Hal ini menunjukkan bahwa Ho ditolak berarti terdapat perbedaan peningkatan kemampuan membaca siswa yang signifikan antara hasil pretest dan posttest peningkatan kemampuan membaca ini dikarenakan dengan penerapan metode SAS.

Setelah dilakukan pretest dan posttest untuk mengetahui peningkatan skor membaca siswa maka dilakukan analisis peningkatan skor sebelum dan sesudah perlakuan yang dihitung dengan uji gain ternormalisasi. Dari analisis terhadap skor gain 
ternormalisasi didapatkan N-Gain kemampuan membaca berjumlah 22,14 dengan rata-rata N-Gain sebesar 0,76. Gain kemampuan membaca siswa kelas II SD yang diperoleh sebesar 0,76 termasuk pada kategori tinggi.

Berdasarkan uraian tersebut dapat diperoleh kesimpulan bahwa terjadi perbedaan dalam pretest maupun posttest dan juga terdapat peningkatan dalam pretest dan posttest tersebut, dengan begitu metode SAS dapat membuat siswa lebih mudah dan lebih menarik dengan apa yang mereka lihat dalam media tersebut karna terdapat terdapat bacaan serta gambar ataupun juga warna yang cerah bagi siswa kelas II. Hal ini sejalan dengan Meisal, U (2016) bahwa dengan menggunakan metode SAS berpengaruh sangat kuat dalam meningkatkan kemampuan membaca permulaan siswa, selain itu metode SAS mampu mengubah pembelajaran biasa yang selama ini berpusat pada guru menjadi pembelajaran yang lebih baik menitik beratkan pada keaktifan siswa dan meningkatkan daya tangkap siswa serta memotivasi siswa yang malas membaca karena pembelajaran dibantu dengan media.

\section{KESIMPULAN}

Berdasarkan hasil analisis dan pembahasan yang telah dilaksanakan disimpulkan bahwa penerapan metode struktural analitik sintetik (SAS) dapat meningkatkan membaca permulaan siswa kelas II SD. Hal ini dapat dilihat dari data yang diperoleh dalam penelitian. Perbedaan ini didasarkan pada hasil uji t. di peroleh $t_{\text {hitung }}$ memenuhi kriteria $t_{\text {hitung }}>t_{\text {tabel }}$ atau 47,191 $>2,045$. Dengan rata-rata $\mathrm{N}$-Gain sebesar 0,76 termasuk pada kategori tinggi, dengan hal ini menunjukan Ho ditolak dan Ha diterima berarti terdapat perbedaan dan peningkatan membaca siswa dengan menerapkan metode struktural analitik sintetik (SAS).

\section{DAFTAR PUSTAKA}

Akhadiah, S, dkk. (1991). Bahasa Indonesia I. Jakarta: Departemen Pendidikan dan Kebudayaan Direktorat Jenderal Pendidikan Tinggi Proyek Pembinaan Tenaga Kependidikan.

Arikunto, S. (2012). Prosedur Pendidikan Suatu Pendekatan Praktek. Jakarta: Rhineka Cipta.

Depdiknas. (2007). Persiapan Membaca dan Menulis Permulaan Melalui Permainan. Jakarta: Departemen Pendidikan Nasional. 
Delfi Syofia, Jismulatif, Fangiana Safitri Diah. (2018). Exploring Personal Reading Histories in Developing Reading Interest of English Study Program Learners of University of Riau. IJELTAL (Indonesian Journal of English Language Teaching and Applied Linguistics) Vol. 2(2), 2018 . www.ijeltal.org

Hairuddin, dkk. (2007). Pembelajaran Bahasa Indonesia. Jakarta: Direktorat Jenderal Pendidikan Tinggi Departemen Pendidikan Nasional.

Kurniaman, O \& Noviana, E. (2016). Metode Membaca SAS (Struktural Analitik Sintetik) dalam Meningkatkan Keterampilan Membaca Permulaan di Kelas I SDN 79 Pekanbaru. Jurnal Primary Pendidikan Guru Sekolah Dasar Fakultas Keguruan dan Ilmu Pendidikan Universitas Riau. 5(2). 149-157. https://ejournal.unri.ac.id/index.php/JPFKIP/article/view/3705

Kurniasih, I \& Sani, B. (2016). Ragam Pengembangan Model Pembelajaran. Jakarta: Kata Pena.

Meisal, U, dkk. (2015). Pengaruh Metode Struktural Analitik Sintetik (SAS) Terhadap Kemampuan Membaca Permulaan Siswa Kelas I SD Negeri 79 Pekanbaru. Jurnal online Mahasiswa Pendidikan Guru Sekolah Dasar. FKIP Universitas Riau. Pekanbaru. 3 (2)

https://jom.unri.ac.id/index.php/JOMFKIP/article/view/12004/0

Mulyati, Y. (2009). Keterampilan Berbahasa Indonesia. Jakarta: Universitas Terbuka.

Mulyono, A. (1991). Pendidikan Bagi Anak Berkesulitan Belajar. Jakarta: Rineka Cipta.

Noor, J. (2011). Metodologi Penelitian. Jakarta: Prenada Media Group.

Solchan, T.W. (2009). Pendidikan Bahasa Indonesia di SD. Jakarta: Universitas Terbuka.

Sudjana. (2005). Metode Statistika. Bandung: Tarsito.

Sugiyono. (2016). Metode Penelitian Kuantitatif, Kualitatif dan R\&D. Bandung: PT. Alfabeta.

Sundayana, R. (2014). Statistika Penelitian Pendidikan. Bandung: Alfabeta.

Supardi. (2013). Aplikasi Statistika dalam Penelitian Edisi Revisi. Jakarta: Change Publication. 